\title{
Serum Cholinesterase Level as a Marker of Systemic Low- Grade Inflammation in Isolated Systolic Hypertension: A Cross-Sectional Study
}

\author{
Williamjeet Sidhu, Lovleen Bhatia, and Kanchan Vohra
}

\section{ABSTRACT}

Background: Autonomic regulation of local and systemic inflammation through the 'cholinergic anti-inflammatory pathway' may have role in persistence of low-grade systemic inflammation in isolated systolic hypertension (ISH). The augmented activity of the enzyme cholinesterase (ChE) leads to degradation of the main anti-inflammatory neurotransmitter 'acetylcholine' of this pathway. Despite the role of inflammation in hypertension, serum level of cholinesterase enzyme has not been determined till now in ISH. The study aimed to measure the serum levels of inflammatory marker $\mathrm{ChE}$ in comparison to high sensitivity $\mathrm{C}$ reactive protein (hsCRP) to predict the presence of low-grade systemic inflammation and their correlation with blood pressure in ISH patients.

Methods: A cross-sectional study was conducted in ISH patients $(n=30$; mean age, 51.00 \pm 1.24 years; male/female $(M / F)$ number=18/12). Age and sex matched healthy subjects $(n=30$, mean age, $51.86 \pm 1.40$ years; $M / F=16 / 14)$ were taken as control. Subjects were divided into three groups based on hsCRP levels; group I (healthy: hsCRP $\leq 1.0 \mathrm{mg} / \mathrm{L}$ ), group IIa (patients with mild inflammation: hsCRP $\leq 1.0 \mathrm{mg} / \mathrm{L}$ ), group IIb (patients with moderate to severe inflammation: hsCRP $1.0-10.0 \mathrm{mg} / \mathrm{L}$ ). Overnight fasting blood samples were collected and $\mathrm{ChE}$ and hsCRP were assessed using Cholinesterase Liqui-Check and hsCRP turbi-latex diagnostic kits, respectively.

Results: hsCRP and ChE levels were found significantly high in hypertensive patients than in healthy subjects $(p<0.05)$. In patients at mild stage of inflammation, there was an increase in both ChE and hsCRP, but not linearly as they had no significant correlation with each other. But at moderate to severe inflammation stage, there was a linear rise in both hsCRP and ChE levels. SBP, DBP and PP were significantly correlated with both $\mathrm{ChE}$ and hsCRP in patients $(p<0.01)$. Moreover, as the SBP was increased from grade I to II, both hsCRP and ChE levels were also increased.

Conclusion: Many factors interplay in propagating inflammatory cascade in ISH and all biomarkers of inflammation may not elevate at same point in time and in linear manner. ChE may act as a marker of low-grade systemic inflammation but its comparison must be tested against a standard marker such as hsCRP in large scale studies for finding its true significance in predicting cardiovascular disease risk.

Keywords: High sensitivity C-reactive protein; Cholinesterase; Isolated systolic hypertension; Low-grade systemic inflammation.
Published Online: November 25, 2020

ISSN: 2593-8339

DOI: $10.24018 /$ ejmed.2020.2.6.534

Mr. Williamjeet Sidhu

Department of Pharmaceutical Sciences and Drug Research, Punjabi University, Patiala, Punjab, India.

(e-mail: singhwilli158@gmail.com)

Dr. Lovleen Bhatia

Department of Internal Medicine, Government Rajindra Medical College and Hospital, Punjab, India.

(e-mail: Lovleen_dr@yahoo.co.in)

Dr. Kanchan Vohra*

Department of Pharmaceutical Sciences and Drug Research, Punjabi University, Patiala, Punjab, India.

(e-mail: kanchanvohra34@gmail.com)

*Corresponding Author

\section{INTRODUCTION}

Isolated systolic hypertension (ISH) defined as elevated systolic blood pressure $(\mathrm{SBP}) \geq 140 \mathrm{mmHg}$ and diastolic blood pressure (DBP) $\leq 90 \mathrm{mmHg}$, is a reflection of increasing arterial stiffness and loss in arterial compliance with age [1]. Elevated SBP has been thought to be more important than DBP as a hazardous factor for cardiovascular morbidity and mortality [2]. Inflammation plays a pivotal role in the growth of hypertension. It has been suggested that inflammation of arteries result in an increased production of cytokines, especially interleukin-6 (IL-6) and activation of clotting factors [3]. Among various inflammatory markers, the well-established, standard, and accurate marker of systemic low-grade inflammation for clinical importance is high sensitivity $\mathrm{C}$-reactive protein (hsCRP). CRP is a plasma protein present in trace amounts $(<1 \mathrm{mg} / \mathrm{L})$ in healthy subjects and is primarily synthesized by liver in response to interleukin (IL)- 6 and IL-1 $\beta$. hsCRP is considered to have direct involvement in ISH [4]. The cardiovascular disease (CVD) risk categories for average hsCRP levels as: low risk $<1.0 \mathrm{mg} / \mathrm{L}$, average risk 1.0-3.0 mg/L, higher risk 3.0 $10.0 \mathrm{mg} / \mathrm{L}$ have been defined by the American Heart 
Association (AHA) and Centre for Disease Control and Prevention (CDCP), 2002 [5].

Autonomic regulation of local and systemic inflammation through the "cholinergic anti-inflammatory pathway", mediates a mechanism consisting of vagus nerve and its major anti-inflammatory neurotransmitter, acetylcholine (Ach) [6]. This pathway mediated by acetylcholine acts by attenuating the production of tumor necrosis factor-alpha (TNF- $\alpha$ ), IL-1, macrophage migration inhibitory factor (MIF), high mobility group protein-1 (HMGB-1) and nuclear factor kappa-B (NF-kB) expression, and by enhancing endothelial nitric oxide synthase (eNOS) production [7]. There are two main types of cholinesterase (ChE) enzymes with different biochemical properties, true cholinesterase, or acetylcholinesterase (AChE) and pseudo cholinesterase or butyrylcholinesterase (BChE) [8]. The augmented activity of these enzymes leads to reduction in the levels of acetylcholine [9]. It had been also demonstrated that activities of enzymes $\mathrm{AChE}$ and $\mathrm{BChE}$ are increased in all conditions involving low-grade systemic inflammation even when plasma, cerebrospinal fluid (CSF) and tissue concentrations of CRP, TNF- $\alpha$, IL- 6 and other markers of inflammation are not elevated significantly [10].

The enzymes activity has been found strongly associated with coronary artery disease and its risk factors [11]. Sato et al. [12] found that hypertensive patients with cholinesterase $<240 \mathrm{U} / \mathrm{L}$ had significantly higher cardiac event rates than those with cholinesterase $>240 \mathrm{U} / \mathrm{L}$. Thus, increase in activities of enzymes $\mathrm{AChE}$ and $\mathrm{BChE}$ in plasma, CSF, leukocytes, platelets may form a reliable, unique, and specific marker to detect chronic low-grade inflammation [10].

Although inflammation has a vital role in ISH, level of Cholinesterase has not been estimated yet in isolated systolic hypertensive patients. The objective of the study was to provide a simple, robust, and new method of detecting systemic low-grade inflammation in the form of detecting cholinesterase enzyme levels in comparison to a traditional marker of inflammation i.e. hsCRP in isolated systolic hypertensive patients.

\section{METHODS}

A prospective, cross-sectional study was conducted in isolated systolic hypertensive patients. The study protocol was approved (approval number- IEC/02-2018/01) by human institutional ethics committee (IEC) of the university and was performed in accordance with the code of Good Clinical Practice and followed STROBE guidelines for observational studies (supplementary file). All the patients had provided written informed consent to participate after a full explanation of the study. Hypertensive patients visiting the hospital for their regular check-up for their ongoing treatment of hypertension during a period of seven months (December 2017 to June 2018) were assessed for eligibility (inclusion/exclusion) criteria of the study (Fig. 1). Simple random sampling design was selected for inclusion of the subjects to exclude bias in selection of patients. Overall, forty patients $(n=40)$ were screened for eligibility criteria. Ten patients did not meet inclusion/exclusion criteria; four patients were having systolic/diastolic hypertension, and six patients also have chronic inflammatory/infectious diseases (Rheumatoid arthritis $(n=3)$, urinary tract infections $(n=2)$ and gastritis $(n=1)$. Finally, thirty patients (age range, 40-65 years) with ISH, defined as SBP $\geq 140 \mathrm{~mm} \mathrm{Hg}$ and DBP $\leq 90$ $\mathrm{mm} \mathrm{Hg}$ according to the Eighth Joint National Committee (JNC)-VIII guidelines for hypertension [13], were recruited. Thirty age- and sex- matched healthy subjects were considered as control. Patients were excluded if having any concomitant chronic inflammatory and/or infectious diseases; systolic/diastolic hypertension regular use of glucocorticoids, NSAIDs, anticholinergic \& cholinergic therapies; history of type- 1 and type- 2 diabetes, uncontrolled hypertension, other cardiovascular \& metabolic disorders (congestive heart failure, stroke, ischemia, arrhythmia, dyslipidaemia, thyroid disorders etc.); alcoholics and smokers; and, pregnant and lactating women.

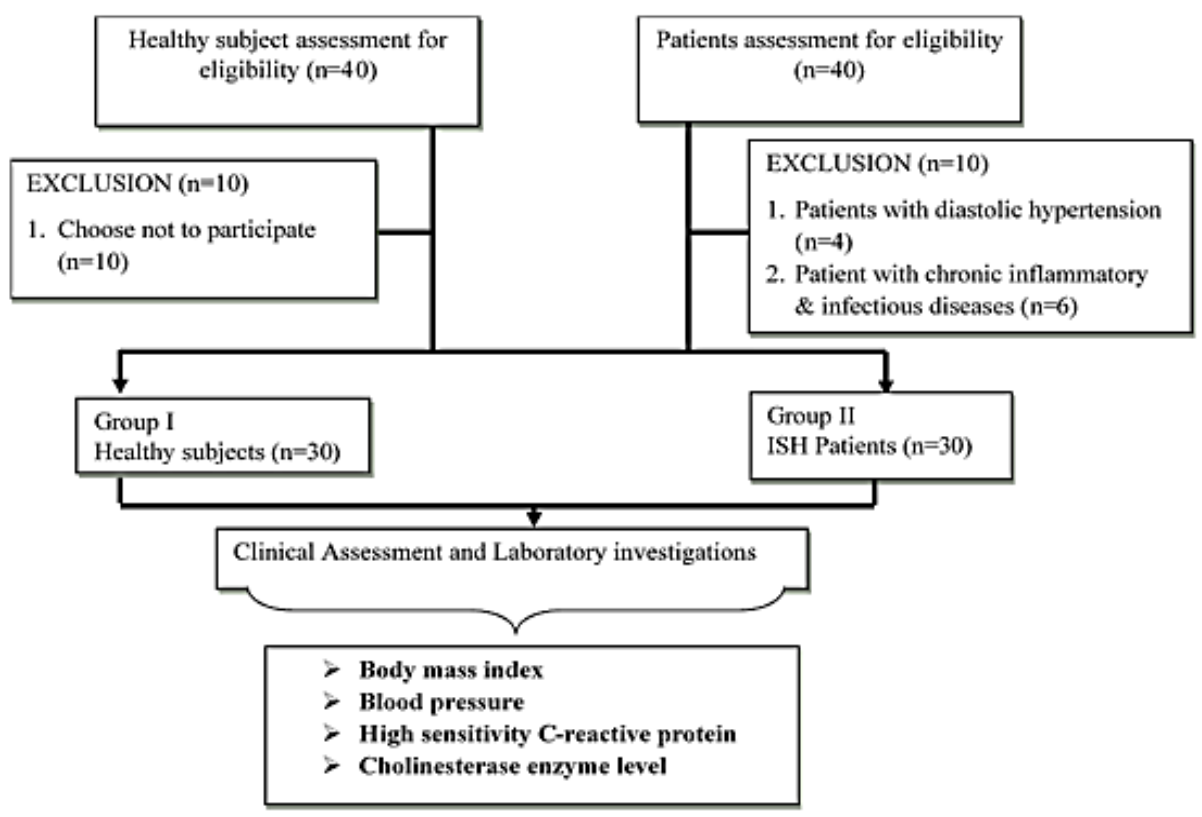

Fig. 1. Flow Chart of patients' inclusion/exclusion criteria. 
Clinical evaluations that included the demographic profile, clinical profile (BP and BMI) and serum biomarkers of inflammation (hsCRP and ChE) were carried out only once (baseline). Overnight fasting blood samples of the patients and healthy subjects were withdrawn, plasma and serum were separated out and stored at $-40{ }^{\circ} \mathrm{C}$ till further analysis. Body weight (kilogram) and height (meter) of all subjects were measured and body mass index (BMI) of subjects was calculated as weight in kilogram/square meter height [14]. The blood pressure was measured using manual mercury sphygmomanometer on the same day just before withdrawing blood sample $(3 \mathrm{ml})$ in all subjects. Serum hsCRP and ChE were measured using hsCRP turbilatex and Cholinesterase Liqui-Check diagnostic kits, respectively (Agappe Diagnostics Ltd., Kerala, India). Main outcome was to find serum ChE level in comparison to serum hsCRP levels in ISH patients and their correlation with blood pressure in ISH patients.

Results were expressed as mean \pm standard deviation (SD). Student's t-test was used to compare the variables between two groups and one-way analysis of variance (ANOVA) between the different groups. The relationship between various clinical variables was examined by Pearson's univariate and multivariate correlation analysis. Multiple linear regression analysis was used to find independent predictors of hsCRP and ChE. All data were analyzed using Graph Pad Prism 7. Statistical significance was accepted at $p \leq 0.05$.

Sample size was determined by considering serum cholinesterase level as primary marker of low-grade inflammation in ISH patients. In our previously published research paper on essential hypertension by Suri et al. [15], cholinesterase levels had been reported as $8859.78 \pm 2574.29 \mathrm{U} / \mathrm{L}$ in healthy subjects. Based on this finding, $25 \%$ elevated level of serum cholinesterase in ISH patients than healthy subjects were considered significant. Thus, to detect a difference of $25 \%$ at $95 \%$ power, a sample size of 30 subjects/group was required.

\section{RESULTS}

The distribution of demographic, clinical and biochemical characteristics of subjects are presented in Table 1. All the eligible patients as per inclusion/exclusion criteria completed the study. There were no missing observations. All the subjects $[\mathrm{n}=60$, male/female $(M / F)=34 / 26]$ included were of age above 40 years (mean age, $52.74 \pm 0.64$ years). None of the patient was newly diagnosed. All patients were known stable cases of ISH and their BP was controlled with medications at the time of recruitment. Patients were taking anti-hypertensive drug therapies according to European Society of Hypertension (ESH), 2014 guidelines for ISH [13]. More than $80 \%$ of patients were on combination of two anti-hypertensive drug therapies. Patients were prescribed to different anti-hypertensive drug regimen as per their clinical assessment by the physicians; metoprolol $25 \mathrm{mg}$ twice a day or combination of amlodipine $(2.5 \mathrm{mg})$ plus atenolol $(25 \mathrm{mg})$ twice a day/ or amlodipine $(2.5 \mathrm{mg})$ plus atenolol $(25 \mathrm{mg})$ twice a day + losartan $25 \mathrm{mg} /$ day.

Subjects were categorized into two major groups, group I ( $n=30$, healthy) and group II $(n=30$, patients). Group II patients were further subcategorized in to two groups, groupIIa $(n=10, M / F=4 / 6)$ and group-IIb $(n=20, M / F=7 / 13)$. This categorization was based upon severity of inflammation described in terms of serum hsCRP levels [(hsCRP $\leq 1.0 \mathrm{mg} / \mathrm{L}$ : low risk (group-IIa) and hsCRP 1.0-10.0 mg/L: moderate-high risk (group-IIb)] [16]. The distribution of demographic and biochemical characteristics of subjects in three groups are presented in table1. Patients were also categorized in to two groups based on their SBP level: Grade I (SBP > 140-150 mmHg) $(\mathrm{n}=13)$ and Grade II (SBP > 150$160 \mathrm{mmHg})(\mathrm{n}=17)$ (Table 2). On comparing the three different groups, hsCRP and ChE levels were significantly high in patients (group- IIa and IIb) as compared to healthy subjects (group I) $(\mathrm{p}<0.01)$ (Table 1). SBP, DBP, pulse pressure (PP), hsCRP and ChE levels were significantly high while moving from mild (group IIa) to higher (group IIb) inflammation (all, $\mathrm{p}<0.01$ ). Moreover, data in Table 2 showed that as the SBP was increased from grade I to II, both hsCRP and ChE levels were also increased.

TABLE1: DEMOGRAPHIC, CLINICAL AND BIOCHEMICAL CHARACTERISTICS OF SUBJECTS

\begin{tabular}{|c|c|c|c|c|c|c|c|}
\hline Parameters & $\begin{array}{c}\text { Group I } \\
\text { (Healthy) }\end{array}$ & $\begin{array}{c}\text { Group II } \\
\text { (Patients) }\end{array}$ & $\begin{array}{l}p \text { value } \\
\text { (II vs. I) }\end{array}$ & $\begin{array}{c}\text { Group I } \\
\text { (Healthy) }\end{array}$ & $\begin{array}{l}\text { Group IIa } \\
\text { (Patients) }\end{array}$ & $\begin{array}{l}\text { Group IIb } \\
\text { (Patients) }\end{array}$ & $\begin{array}{c}p \\
\text { IIa vs. I* } \\
\text { IIb vs. I^ } \\
\text { IIb vs. IIa }^{\#}\end{array}$ \\
\hline No. of subjects & 30 & 30 & & 30 & 10 & 20 & \\
\hline & $\begin{array}{c}\text { hsCRP } \\
(\leq 1 \mathrm{mg} / \mathrm{L})\end{array}$ & $\begin{array}{c}\text { hsCRP } \\
(\leq 10 \mathrm{mg} / \mathrm{L})\end{array}$ & & $\begin{array}{c}\text { hsCRP } \\
(\leq 1 \mathrm{mg} / \mathrm{L})\end{array}$ & $\begin{array}{c}\text { hsCRP } \\
(\leq 1 \mathrm{mg} / \mathrm{L})\end{array}$ & $\begin{array}{c}\text { hsCRP } \\
(\leq 10 \mathrm{mg} / \mathrm{L})\end{array}$ & \\
\hline Male/Female no. & $16 / 14$ & $18 / 12$ & & $16 / 14$ & $4 / 6$ & $7 / 13$ & \\
\hline Age (years) & $51.86 \pm 1.40$ & $51.00 \pm 1.24$ & 0.63 & $51.86 \pm 1.40$ & $53.00 \pm 2.78$ & $51.90 \pm 3.96$ & NS \\
\hline BMI $\left(\mathrm{Kg} / \mathrm{m}^{2}\right)$ & $21.20 \pm 1.04$ & $24.62 \pm 1.36$ & $<0.01 *$ & $21.20 \pm 1.04$ & $24.22 \pm 1.20$ & $24.94 \pm 1.16$ & $<0.01^{* \wedge}$ \\
\hline $\mathrm{SBP}(\mathrm{mmHg})$ & $121.62 \pm 1.37$ & $144.10 \pm 1.31$ & $<0.01 *$ & $121.62 \pm 1.37$ & $135.22 \pm 1.09$ & $150.00 \pm 5.96$ & $<0.01^{* \wedge \#}$ \\
\hline $\mathrm{DBP}(\mathrm{mmHg})$ & $81.66 \pm 1.11$ & $83.91 \pm 1.24$ & $<0.01 *$ & $81.66 \pm 1.11$ & $78.20 \pm 0.81$ & $84.83 \pm 1.15$ & $<0.01^{* \wedge \#}$ \\
\hline $\mathrm{PP}(\mathrm{mmHg})$ & $43.41 \pm 1.50$ & $60.66 \pm 6.66$ & $<0.01 *$ & $43.41 \pm 1.50$ & $53.55 \pm 1.42$ & $68.88 \pm 1.69$ & $<0.01^{\text {*^\# }}$ \\
\hline hsCRP (mg/L) & $0.56 \pm 0.01$ & $2.44 \pm 2.25$ & $<0.01 *$ & $0.56 \pm 0.01$ & $0.78 \pm 0.02$ & $4.11 \pm 1.77$ & $<0.01^{\wedge \#}$ \\
\hline $\mathrm{ChE}(\mathrm{IU} / \mathrm{L})$ & $9282.27 \pm 124.51$ & $12866.00 \pm 200.62$ & $<0.01 *$ & $9282.27 \pm 124.51$ & $10897.00 \pm 200.66$ & $14163.00 \pm 259.87$ & $<0.01^{\text {*^\# }}$ \\
\hline
\end{tabular}

Results presented as mean $\pm \mathrm{SD} ; * p$ considered significant at $p<0.05$.

TABLE 2: hSCRP AND CHE LEVELS IN HEALTHY AND ISH PATIENTS

\begin{tabular}{|c|c|c|c|c|c|c|}
\hline & \multirow{2}{*}{$\begin{array}{l}\text { Healthy Control (C) } \\
\text { SBP <120 mmHg }\end{array}$} & \multirow{2}{*}{$\begin{array}{c}\text { ISH (Stage I) } \\
\text { SBP }>140-150 \mathrm{mmHg}\end{array}$} & \multirow{2}{*}{$\begin{array}{c}\text { ISH (Stage II) } \\
\text { SBP }>150-160 \mathrm{mmHg}\end{array}$} & \multicolumn{3}{|c|}{$p$ value } \\
\hline & & & & I vs. C & II vs. I & II vs. C \\
\hline hsCRP & $0.56 \pm 0.01$ & $1.58 \pm 0.82$ & $5.83 \pm 0.05$ & $<0.01^{*}$ & $<0.01 *$ & $<0.01 *$ \\
\hline ChE & $9282.27 \pm 124.51$ & $12477.00 \pm 599.04$ & $14349.00 \pm 129.59$ & $<0.01 *$ & $<0.01 *$ & $<0.01 *$ \\
\hline
\end{tabular}

Results are expressed as mean \pm SD. Statistical significance accepted at $\mathrm{p}<0.05$. hsCRP expressed as mg/L and ChE as IU/L. 
Univariate correlation analysis was used to find association between various variables. Fig. 2 shows the scatter plots of statistically significant correlation of conventional risk factors (SBP, PP and DBP) with hsCRP (Fig. 2a) and ChE (Fig. 2b) in ISH patients (group II) (all $p$ $<0.001$ ). In ISH patients' subgroup (group IIb: hsCRP 1$10 \mathrm{mg} / \mathrm{L})$, SBP and PP, not DBP, were significantly correlated with both hsCRP (Fig. 2c) and ChE (Fig. 2d) $(\mathrm{p} \leq 0.01)$. Age and BMI did not show any significant correlation with neither hsCRP nor ChE in any group/subgroup ( $p>0.05$ ), except BMI with $\mathrm{ChE}(\mathrm{r}=0.57$, $\mathrm{p}<0.01)$ in healthy subjects.
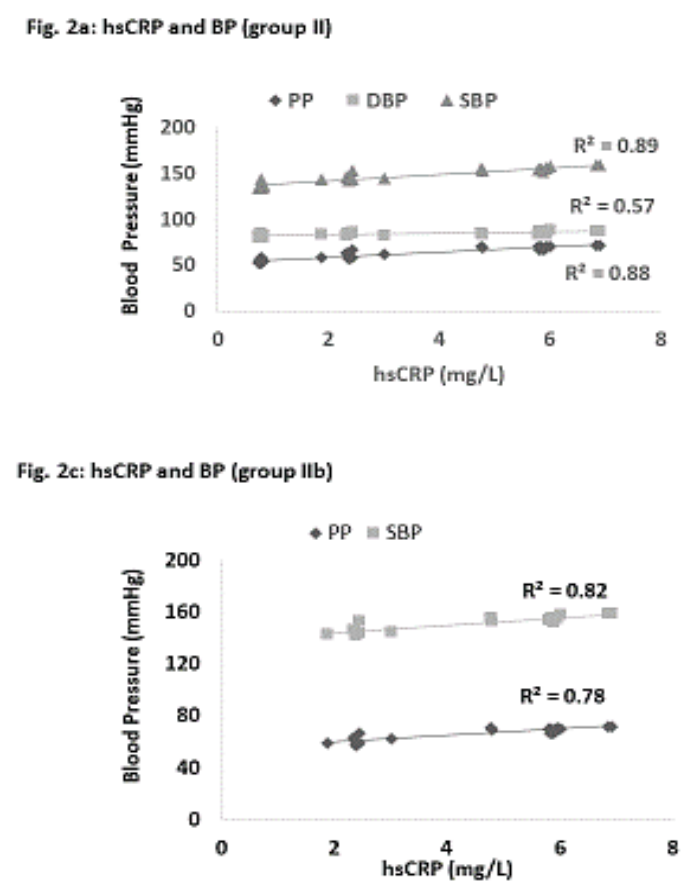

Linear regression analysis data also revealed association of hsCRP with ChE. Fig. 3 shows regression plots of hsCRP and $\mathrm{ChE}$ in different groups. Overall, at any stage of mild to severe inflammation, ChE was linearly correlated with hsCRP in ISH patients ( $p \leq 0.01)$ (Fig. 3b). hsCRP and ChE were not correlated with each other neither in healthy subjects (group I) nor in patients (group IIa) where hsCRP level was less than $1 \mathrm{mg} / \mathrm{L}$ (Fig. $3 \mathrm{a}$ and $3 \mathrm{c})(\mathrm{p}>0.05)$. As hsCRP levels were increased from 1 to $10 \mathrm{mg} / \mathrm{l}$ (group IIb) correlation between $\mathrm{ChE}$ and hsCRP was also strengthened and reached linearity $(\mathrm{p}<0.01)$ (Fig. 3d).

Fig. 2. Scatter plots of correlation between various variables in patients.

Fig. 2 describes statistically significant correlation ( $\mathrm{p}<0.01$ ) between hsCRP and BP (group II): Fig. 2a; ChE and BP (group II): Fig 2b; hsCRP and BP (group IIb): Fig. 2c; ChE and BP (group IIb): Fig 2d.

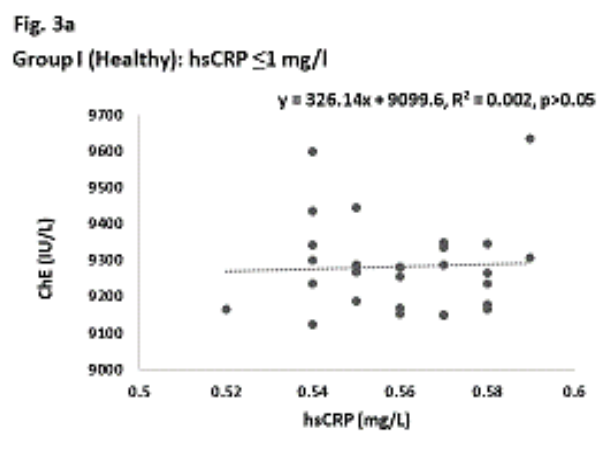

Fig. 3c

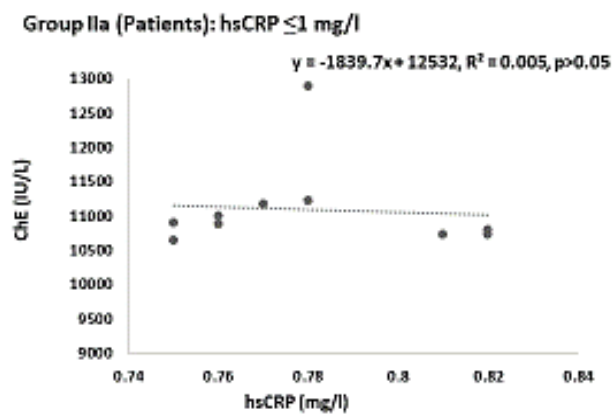

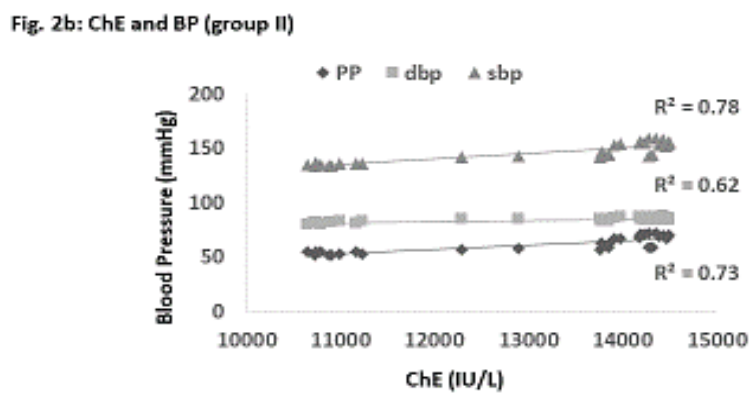

Fig. 2d: ChE and BP (Eroup IIb)

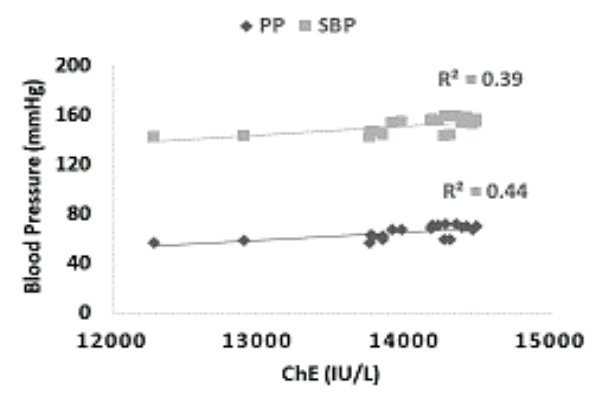

Fig. 3. Regression plots of hsCRP with ChE in different groups.

Fig. 3 describes the association between hsCRP and ChE in healthy subjects (fig. $3 a$ ) and patients (fig. 3b, 3c and 3d). 
Multivariate linear regression was also used to find independent linear predictors of $\mathrm{ChE}$ and hsCRP in ISH patients. In multivariate regression model, PP was collinear with other independent variables, so it was removed from the regression model for analysis. Finally, only SBP was found linear and independent predictor of both hsCRP $(\mathrm{p}<0.001)$ and ChE $(\mathrm{p}<0.001)$. Age, BMI, DBP and PP were not found linear predictors of neither hsCRP nor ChE (Table3). Thus, in patients with mild inflammation, increase in ChE was not associated with a linear rise in hsCRP. But increase in inflammation severity from mild to severe form also lead to linear rise in both hsCRP and ChE levels.

\begin{tabular}{ccccc}
\multicolumn{5}{c}{ TABLE 3: PREDICTORS OF HSCRP AND CHE IN PATIENTS } \\
\hline & Variable & $\begin{array}{c}\text { Coefficient } \\
(\beta)\end{array}$ & $\mathrm{t}$ & $P$ \\
\hline \multirow{4}{*}{ Determinants of } & SBP & 0.26 & 8.01 & $<0.001^{*}$ \\
hsCRP & DBP & -0.09 & -0.72 & 0.47 \\
& Age & 0.01 & 0.10 & 0.92 \\
& BMI & -0.02 & -0.15 & 0.87 \\
\hline \multirow{2}{*}{ Determinants of } & SBP & 135.31 & 4.35 & $<0.001^{*}$ \\
ChE & DBP & 115.05 & 0.95 & 0.35 \\
& Age & -26.55 & -0.47 & 0.64 \\
& BMI & -61.35 & -0.46 & 0.65 \\
\hline
\end{tabular}

*p statistically significant values.

\section{DISCUSSION}

The last decade has shown an increase in the relevance of inflammation and its mediators in vascular biology [17]. Both local and systemic inflammation play a significant role in the pathogenesis of hypertension [4]. In the present study, it was tried to test the serum levels of inflammatory marker ChE in comparison to a traditionally robust inflammatory marker hsCRP to examine the possible role of low-grade systemic inflammation in ISH patients. The finding of high serum hsCRP and ChE levels and their positive correlation with each other revealed that as hsCRP level increased from mild to severe inflammation, ChE levels also increased linearly with hsCRP. Inflammation enhances the risk of CVD, thus increase in CRP and ChE level predict the increased risk of CVD.

Many studies have reported a positive association between hsCRP and blood pressure [4], [18], [19], but data is scarce about $\mathrm{ChE}$ levels and its association with blood pressure in ISH. This association is likely confounded by other risk factors, such as age, sex, and BMI. A few studies have reported the controversial findings of $\mathrm{BChE}$ activity and the risk of CVDs, two studies report the increased $\mathrm{BChE}$ activity as a risk for CVDs [11], [20] and the other two studies concluded opposite to this [21], [22].

Assayag et al. [23] reported lower BChE activities associated with an adverse outcome in patients suffering from acute ischemic stroke, suggesting that higher BChE activities reflect a better recovery process. Stojanov et al. [24] had reported that lowered levels of $\mathrm{BChE}$ are related with greater mortality in hemodialysis patients. The authors found that ChE levels were high in hypertensive patients as compared to control subjects; but there was no significant difference in ChE levels when, SBP levels were increased. In-contrast, in the present study, ChE levels were elevated as per rise in SBP levels.
The inter-correlation of conventional risk factors revealed that only BMI was significantly correlated with $\mathrm{ChE}$ in healthy subjects. This is in support to the previous studies which concluded that adipose tissue releases proinflammatory markers into the circulation such as IL-6. Patients with high BMI have adipose tissue in abundance. Hence, IL-6 triggers the production of protein from the liver which leads to increased level of $\mathrm{BChE}$ as it is synthesized in liver [25]. Present study could not show any association of BMI with ChE and hsCRP in ISH patients. But SBP, DBP and PP all were highly correlated with both hsCRP and ChE. Moreover, patients' subgroups analysis too revealed significant association of SBP and PP with both hsCRP and $\mathrm{ChE}$ in group IIb (patients having moderate to severe inflammation). It seems that high blood pressure alone acts as a significant initiator for accelerated low-grade systemic inflammation or vice-versa.

In the present study, age did not show any association with either hsCRP or ChE revealing that inflammation is not dependent on age. In support of our finding, a study had reported no association of age with serum ChE levels in healthy subjects [26] and other study reported no association in diabetic patients [27]. But in contrast three studies had found a positive co-relation of age with both hsCRP [28], [29] and $\mathrm{ChE} \mathrm{[30]} \mathrm{in} \mathrm{healthy} \mathrm{subjects.}$

Present study showed no correlation between hsCRP and $\mathrm{ChE}$ at mild stage of inflammation ( $\mathrm{hsCRP} \leq 1 \mathrm{mg} / \mathrm{l}$ ) in both patients and heathy subjects, but a linear correlation was found when inflammation progressed from mild to severe level (hsCRP $\geq 1$ but $\leq 10 \mathrm{mg} / \mathrm{l}$ ). In contrast of above, a study by Lampón et al. in CVD patients depicted significant positive correlation between hsCRP and $\mathrm{ChE}$ at mild inflammatory stage (hsCRP $\leq 1 \mathrm{mg} / \mathrm{l})$ and significant negative correlation at severe stage (> 3-10 mg/L) [31]. Similarly, De Bona et al., found no correlation between hsCRP and BChE activity in metabolic syndrome patients [32]. The above heterogenous findings of $\mathrm{ChE}$ and hsCRP correlation suggests that many factors interplay in propagating inflammatory cascade and all bio-markers of inflammation may not elevate or drop at same point in time and in linear manner. These results may signify that inflammation in ISH patients cannot be categorized based only on hsCRP or ChE values.

Present findings could not reach to a concrete conclusion to make any CVD risk prediction based on serum ChE levels. This might be due to insufficient total sample size in all groups, not including other inflammatory biomarkers and absence of other concurrent diseases. A large sample size study is required to make results more predictable. Many factors such as sensitivity, specificity, cost of estimation, methodology, standardization etc. need to be considered that will ultimately help in proper defining the diagnostic utility of $\mathrm{ChE}$ as a good biomarker. 


\section{CONCLUSION}

Presently, we explored the serum cholinesterase level in comparison to hsCRP as a marker of systemic low-grade inflammation in ISH subjects. Though small sample size may not provide true value of study, it may act as basic preliminary data-base for future studies. Although $\mathrm{ChE}$ levels were found high in ISH patients, categorized on the basis of severity of inflammation [mild (hsCRP $<1 \mathrm{mg} / \mathrm{L}$ ) and moderate to severe (hsCRP $1-10 \mathrm{mg} / \mathrm{L}$ )], there was no linear correlation found between hsCRP and $\mathrm{ChE}$ at mild inflammatory stage, but a linear correlation was found at moderate-severe inflammatory stage. This may suggest that both hsCRP and $\mathrm{ChE}$ are good markers for reflecting low-grade inflammation, but their synthesis and release is not dependent on each other. Moreover, rise in both hsCRP and ChE levels along with SBP from grade I to grade II may suggest low-grade systemic inflammation as an inherent feature of hypertension.

\section{LIST OF ABBREVIATIONS}

ChE: Cholinesterase

hsCRP: High sensitivity C-reactive protein

SBP: Systolic Blood Pressure

ISH: Isolated systolic hypertension

BMI: Body mass index

DBP: Diastolic blood pressure

PP: Pulse pressure

\section{REFERENCES}

[1] O'Rourke MF, Nichols WW. Aortic diameter, aortic stiffness, and wave reflection increase with age and isolated systolic hypertension. Hypertension. 2005;45:652-8.

[2] Acelajado MC, Calhoun DA. Resistant hypertension, secondary hypertension and hypertensive crises: Diagnostic evaluation and treatment. Cardiol Clin. 2010;28:639-54

[3] Garrido-Urbani S, Meguenani M, Montecucco F, Imhof BA Immunological aspects of artherosclerosis. Semin Immunopathol. 2014;36:73-91.

[4] Ridker PM. High-sensitivity C-reactive protein: potential adjunct for global risk assessment in the primary prevention of cardiovascular disease. Circulation. 2001; 103:1813-8.

[5] Young D, Camhi S, Wu T, Hagberg J, Stefanick M. Relationships among changes in $\mathrm{C}$-reactive protein and cardiovascular disease risk factors with lifestyle interventions. NutrMetab Cardiovasc Dis. 2013;23:857-63

[6] Rosas-Ballina M, Tracey KJ. Cholinergic control of inflammation. J Intern Med. 2009; 265:663-79.

[7] Tracey KJ. Physiology and immunology of the cholinergic antiinflammatory pathway. J Clin Invest. 2007;117:289-96.

[8] Davis L, Britten JJ, Morgan M. Cholinesterase: Its significance in anaesthetic practice. Anaesthesia. 1997;52:244-60.

[9] Das UN. Acetylcholinesterase \& butyryl-cholinesterase as possible markers of low- grade systemic inflammation. Med Sci Monit. 2007; 13:RA214- 21.

[10] Rao AA, Sridhar GR, Das UN. Elevated butyryl cholinesterase and acetylcholinesterase may predict the development of type 2 diabetes mellitus and Alzheimer's disease. Med Hypotheses. 2007;69:1272-6.

[11] Alcantara VM, Chautard-Freire-Maia EA, Scartezini M, Cerci MS Braun-Prado K, Picheth G. Butyryl-cholinesterase activity and risk factors for coronary artery disease. Scand J Clin Lab Invest 2002;62:399-04.

[12] Sato KK, Hayashi T, Maeda I, Koh H, Harita N, Uehara S, et al. Serum butyryl-cholinesterase and the risk of future type 2 diabetes: the Kansai Healthcare Study. Clin Endocrinol. 2014;80:362-7.

[13] James PA, Oparil S, Carter BL, Cushman WC, Dennison-Himmelfarb $\mathrm{C}$, Handler J, et al. Evidence based guideline for the management of high blood pressure in adults: report from the panel members appointed to the eight joint national committee (JNCVIII). JAMA. 2014;311:507-20

[14] Mei Z, Grummer-Strawn LM, Pietrobelli A, Goulding A, Goran MI, Dietz WH. Validity of body mass index compared with other bodycomposition screening indexes for the assessment of body fatness in children and adolescents. Am J Clin Nutr. 2002; 75:978-85.

[15] Suri A, Samplay NS, Singh R, Varma S, Singh H, Vohra K Cholinesterase: Not a robust marker of systemic low-grade inflammation in hypertension. Int J Adv Res Sci Technol. 2015;4:322 9

[16] Jialal I, Devaraj S, Venugopal SK. C-reactive protein: risk marker or mediator in atherothrombosis? Hypertension. 2004;44:6-11.

[17] Libby P, Ridker PM, Maseri A. Inflammation and atherosclerosis. Circulation. 2002;105:1135-43.

[18] Ridker PM, Buring JE, Shih J, Matias M, Hennekens CH. Prospective study of C-reactive protein and the risk of future cardiovascular events among apparently healthy women. Circulation. 1998;98:731-3.

[19] Ridker PM, Hennekens CH, Buring JE, Rifai N. C-reactive protein and other markers of inflammation in the prediction of cardiovascular disease in women. N Engl J Med. 2000;342:836-43.

[20] Calderon-Margalit R, Adler B, Abramson JH, Gofin J, Kark JD.Butyrylcholinestrase activity, cardiovascular risk factors and mortality in middle aged and elderly men and women in Jerusalem. Clin Chem. 2006;52:845-52.

[21] Lampon N, Hermida-Cadahia EF, Riveiro A, Tutor JC. Association between butyrylcholinesterase and systemic low-grade inflammation. Ann Hepatol. 2012;11:356-63.

[22] Goliasch G, Haschemi A, Marculescu R, Endler G, Maurer G, Wagner $\mathrm{O}$ et al. Butyrylcholinesterase activity predicts long-term survival in patients with coronary artery disease. Clin Chem. 2012;58:1055-8.

[23] Assayag BE, Shenhar-Tsarfaty S, Ofek K, Soreq L, Bovo I, Shopin L, et al.Serum cholinesterase activities distinguish between stroke patients and controls and predicts 12- month mortality. Mol Med 2010;16:278-86

[24] Stojanov M, Stefanovic A, Dzingalasevic G, Mandic-Radic S Prostran M.Butyrylcholinestearse activity in young men and women: association with cardiovascular risk factors. Clin Biochem. 2011;44:623-6.

[25] Fiesta A, D’Agostino R Jr, Williams K, Karter AJ, Mayer-Davis EJ, Tracy RP, et al.The relation of body fat mass and distribution to markers of chronic inflammation. Int J Obes Relat Metab Disord. 2001;25:1407-15

[26] Vallianou NG, Evangelopoulos AA, Bountziouka V, Bonou MS, Katsagoni C, Vogiatzakis ED, et al. Association of butyrylcholinesterase with cardiometabolic risk factors among apparently healthy adults. J Cardiovasc Med (Hagerstown). 2014; 15:377-83

[27] Abbott CA, Mackness MI, Kumar S, Olukoga AO, Gordon C, Arrol $\mathrm{S}$, et al. Relationship between serum butyrylcholinesterase activity, hypertriglyceridemia and insulin sensitivity in diabetes mellitus. Clin Sci (Lond). 1993;85:77-81.

[28] Milan-Mattos JC, Anibal FF, Perseguini NM, Minatel V, RehderSantos P, Castro CA, et al. Effects of natural aging and gender on proinflammatory markers. Braz J Med Biol Res. 2019;52(9): e8392.

[29] Nadrowski P, Chudek J, Skrzypek M, Puzianowska-Kuźnicka M, Mossakowska M, Wieccek A, et al. Associations between cardiovascular disease risk factors and IL-6 and hsCRP levels in the elderly. Exp Gerontol. 2016;85:112-7.

[30] Randell EW, Mathews MS, Zhang H, Seraj JS, Sun G. Relationship between serum butyrylcholinesterase and the metabolic syndrome. Clin Biochem. 2005;38:799-05.

[31] Lampón N, Hermida-Cadahia EF, Riveiro A, Tutor JC. Association between butyrylcholinesterase activity and low-grade systemic inflammation. Ann Hepatol. 2012;11:356-363.

[32] De Bona KS, Bonfanti G, Bitencourt PE, Cargnelutti LO, da Silva PS, De Lucca L, et al. Butyrylcholinesterase and $\gamma$-glutamyl transferase activities and oxidative stress markers are altered in metabolic syndrome, but are not affected by body mass index. Inflammation. $2013 ; 36: 1539-47$. 


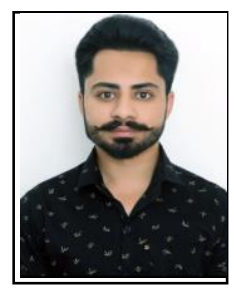

Williamjeet Sidhu Post-graduated from Punjabi University, Patiala, (Punjab) in Pharmaceutical Sciences program in 2018. I am working as an ASSISTANT PROFESSSOR at School of Pharmaceutical sciences, RIMT University (Fatehgarh-Sahib, Punjab) and have two years of professional experience in teaching. I have a strong interest in the field of research and clinical practice. I have proceeding in multifarious national as well as international conferences including; COVID-19: Challenges in testing prophylaxis \& management, Role on IQAC in quality sustenance, Current Perspectives of Microbial Diseases 2020, Good governance, Trends \& changes in pharmaceutical education \& research, and Nano-therapeutics \& Crystal engineering. I have been awarded by Indian Pharmacy Graduates' Association (IPGA), Udaipur for valuable contribution.

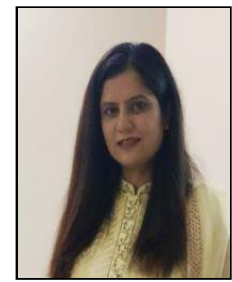

Dr. Lovleen Bhatia is Professor in Dept. of Medicine at the Govt. Rajindra Medical College and hospital, Patiala (Punjab). She has guided and motivated numerous graduates as well as postgraduate students for the diverse research activities. She has been awarded by various awards for her wonderful research work in medicine.

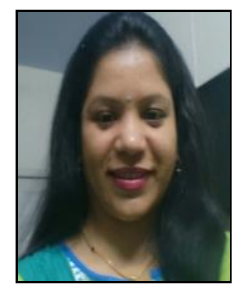

Dr. Kanchan Vohra is an Associate professor of Pharmacy Practice since 2004 at Department of Pharmaceutical Sciences and Drug Research, Punjabi University, Patiala. Major research area is clinical research in cardiology, diabetology and Rheumatology related fields. She has guided many post-graduate students for research in various disciplines of Pharmacy Practice. 